\title{
Changes in perceived pain severity during interdisciplinary treatment for chronic pain
}

\author{
John Kowal $\mathrm{PhD}^{1,2}$, Keith G Wilson $\mathrm{PhD}^{1,2}$, Celia M Geck BA², \\ Peter $\mathrm{R}$ Henderson $\mathrm{PhD}^{1,2}$, Joyce $\mathrm{L} \mathrm{D}^{\prime}$ Eon $\mathrm{PhD}^{1,2}$
}

\begin{abstract}
J Kowal, KG Wilson, CM Geck, PR Henderson, JL D’Eon. Changes in perceived pain severity during interdisciplinary treatment for chronic pain. Pain Res Manage 2011;16(6):451-456.
\end{abstract}

BACKGROUND: There is good support for the effectiveness of interdisciplinary chronic pain management programs in improving functional outcomes; however, relatively little is known about patients who report deterioration following participation in such programs.

OBJECTIVES: The present retrospective study investigated patients' reports of increased pain severity during participation in a cognitivebehaviourally oriented, outpatient treatment for chronic pain.

METHODS: Participants $(\mathrm{n}=280)$ completed a four-week, group-based, interdisciplinary chronic pain self-management program at a rehabilitation hospital. They completed pre- and post-treatment questionnaires, which included global change ratings of pain severity and clinically-relevant measures, including pain intensity ratings, functional limitations, pain catastrophizing and self-efficacy.

RESULTS: Statistically significant pre-post improvements were observed for all study variables. Almost all patients reported global improvement overall. Nevertheless, a subset of patients $(n=99)$ reported increased pain severity on global ratings. These individuals were characterized by lower self-efficacy at baseline.

CONCLUSIONS: Participants endorsed significant pre- and post-treatment improvements in all domains. Nevertheless, some participants reported deterioration. The findings shed light on variables associated with negative treatment outcomes and have practical applications for interdisciplinary chronic pain management programs.

Key Words: Chronic pain; Cognitive behavioural therapy; Deterioration; Interdisciplinary; Treatment outcomes; Worsening

\section{Les modifications à la douleur perçue pendant le traitement interdisciplinaire de la douleur chronique}

HISTORIQUE : On soutient l'efficacité des programmes interdisciplinaires de prise en charge de la douleur chronique pour améliorer des issues fonctionnelles, mais on ne sait pas grand-chose des patients qui déclarent voir leur état se détériorer après avoir participé à de tels programmes.

OBJECTIFS : La présente étude rétrospective a porté sur les déclarations d'augmentation de la gravité de la douleur par les patients, alors qu'ils participaient à un traitement cognitif à orientation behaviorale de leur douleur chronique en consultations externes.

MÉTHODOLOGIE : Les participants $(\mathrm{n}=280)$ ont participé à un programme interdisciplinaire de prise en charge autonome de leur douleur chronique dans un hôpital de réadaptation. Ils ont rempli un questionnaire avant et après le traitement, qui incluait une évaluation globale de la modification de la gravité de leur douleur et des mesures pertinentes sur le plan clinique, dont l'évaluation de l'intensité de la douleur, les limites fonctionnelles, la catastrophisation de la douleur et l'autoefficacité.

RÉSULTATS : Les chercheurs ont observé des améliorations avant-après statistiquement significatives à l'égard de toutes les variables de l'étude. Presque tous les patients ont déclaré une amélioration globale. Néanmoins, un sous-groupe de patients $(\mathrm{n}=99)$ a fait état d'une augmentation de la gravité de la douleur dans le cadre des évaluations globales. Ces personnes se caractérisaient par une autoefficacité plus faible en début d'étude.

CONCLUSIONS : Les participants ont corroboré des améliorations significatives avant et après le traitement dans tous les domaines. Néanmoins, certains participants ont déclaré une détérioration de leur état. Ces observations jettent la lumière sur les variables associées aux issues négatives du traitement et ont des applications pratiques dans le cadre des programmes de prise en charge interdisciplinaire de la douleur chronique.

informed interventions, including those embedded in interdisciplinary programs, suggest they are the treatment of choice for individuals experiencing persistent pain.

Recently, the Initiative on Methods, Measurement, and Pain Assessment in Clinical Trials (IMMPACT) established consensus recommendations for research on chronic pain (12-14). The six core domains identified were pain, physical functioning, emotional functioning, participant ratings of improvement, symptoms and adverse events, and participant disposition. The establishment of these six standard domains enables meaningful comparisons across studies and more consistency in evaluating treatment outcomes.

Although the majority of outcome research focuses on improvements in various domains, there is a potential for such interventions to be associated with undesirable consequences. These consequences could include increased pain brought on, for example, by increases in physical function that are encouraged in interdisciplinary programs. In this regard, one could expect that certain individuals might experience increased pain despite experiencing improvements in other domains. Evaluating adverse events is common in pharmacological research, especially in terms of drug tolerance, patient tolerability and neurotoxic side-effects (15); however, deterioration is rarely examined in
There is good empirical support for the efficacy and effectiveness of CBT-based approaches, as evaluated by short- and long-term outcomes in multiple domains $(3,4,8-11)$. Patients treated in multidisciplinary settings founded on CBT principles function significantly better than waitlisted or untreated patients, and patients treated using a unimodal approach. The substantiated efficacy and effectiveness of CBT gy, University of Ottawa, Ottawa, Ontario

Correspondence: Dr John Kowal, Psychology, The Ottawa Hospital Rehabilitation Centre, 505 Smyth Road, Ottawa, Ontario K1H 8M2.

Telephone 613-737-7350, ext 75317, fax 613-737-7056, e-mail jkowal@ottawahospital.on.ca 
nonpharmacological interventions, such as CBT-informed treatment for chronic pain.

Recent articles suggest that further examination of negative psychotherapeutic effects is warranted (16-18). One study in particular indicated that a small percentage of chronic pain patients (ie, $1 \%$ to $2 \%$ ) admitted to a four-week, in-patient pain management program reliably deteriorated during treatment (10). Less clear was which, if any, patient characteristics were associated with patients' reports of getting worse. There is a paucity of research examining factors associated with declines following nonpharmacological treatment for chronic pain. This line of inquiry could shed light on potential aspects of function that programs do not improve and, in the process, provide clues as to how treatment outcomes could be enhanced. It could also illuminate individual differences in participants' responses to treatment. Accordingly, the present study examined patients' reports of worsening in pain severity following an interdisciplinary, CBToriented chronic pain management program.

\section{Subjects}

\section{METHODS}

Participants in the present retrospective study were consecutive patients admitted to an interdisciplinary chronic pain management program at a rehabilitation hospital in Ottawa, Ontario. Data collection took place from September 2005 to August 2008. The main inclusion criteria were the presence of chronic pain (defined as pain lasting for at least three months and as diagnosed by a physiatrist), readiness to engage in a self-management program, fluent in English or French, and able to participate from medical and psychological perspectives. Patients were excluded if they had a primary substance abuse problem, their pain symptoms were exclusive to headaches, gynecological/urinary problems or gastrointestinal difficulties, and/or they were not ready to engage in treatment (ie, they were actively seeking medical interventions or were unwilling or unable to participate in a group-based program).

A nurse clinician triaged all new referrals. Interested and eligible participants attended a 90 min information session during which the treatment approach, program philosophy and therapeutic goals were described. Participants had the opportunity to pose questions regarding the program and their participation. Following the information session, patients expressing a desire to participate in the program completed a pain history questionnaire assessing pain symptoms, pain-related treatment history, physical functioning and sociodemographic characteristics. Participants who returned their completed pain history questionnaire were scheduled to attend a consultation with a physiatrist and nurse clinician. Patients deemed medically stable enough to participate in treatment were subsequently scheduled for the assessment/education phase (see below).

\section{Treatment program}

Assessment/education phase: The four-week chronic pain management program consisted of two basic phases: assessment/education and treatment. The assessment/education phase took place over four halfdays. Patients were seen both individually and in a group format by an interdisciplinary team consisting of health care professionals from psychology, social work, occupational therapy and physiotherapy. The week involved formal assessment, including clinical interviews, and educational sessions on pain physiology and pain management principles and strategies.

Treatment phase: The treatment phase was three weeks in duration and, for most patients, immediately followed the assessment/ education phase. This phase consisted of group sessions offered by several disciplines, including psychology, nursing, physiotherapy, occupational therapy, vocational rehabilitation, recreational therapy and social work. It also involved a series of educational lectures offered one morning each week. The treatment team met several times per week to discuss patients' progress and treatment planning. In addition to the treatment groups, patients met weekly with at least one interdisciplinary team member for feedback and to discuss treatment progress and goals.

The overall treatment program was based on CBT principles. The overarching goal was to help patients manage their chronic pain more effectively. This was accomplished by the following: providing education about chronic pain and disability management; modifying activity levels to help patients remain active and work within their tolerances; improving physical fitness levels, including strength, flexibility and posture; and enhancing emotional functioning. The majority of patients participated in the full treatment program. For some patients, especially those with limited physical abilities and tolerances, a less intense (ie, modified and extended) treatment program was offered, typically lasting six weeks.

\section{Procedures}

All participants completed a battery of questionnaires at the start of the assessment/education phase. Patients who continued into the treatment phase completed a battery of postprogram questionnaires at the end of their final treatment week. The content and structure of the program remained unchanged throughout the duration of data collection. The present research, which was based on archival data, was approved by the institution's research ethics board.

\section{Measures}

Sociodemographic characteristics: Basic sociodemographic information was collected, including age, sex, marital status, work status and education level.

Pain intensity ratings: Participants rated their pain intensity on a four-item scale assessing current, worst, least and average pain. Average pain was evaluated over the previous two weeks. Responses to each item were recorded on an 11-point numerical rating scale, ranging from 0 (no pain) to 10 (as intense as you could imagine) (19). The four items were summed to derive a single composite score with values ranging from 0 to 40 . Higher scores denote greater pain intensity. This type of approach has good psychometric properties and has been used in many studies (20). Patients were also asked about the duration of their pain symptoms.

Functional limitations: Patients' functional limitations were assessed using an adapted version of a scale recommended by the Task Force on Records and Data Retrieval of the International Association for the Study of Pain (21). The modification to this scale was based on pilot psychometric data collected in the current treatment program suggesting that a few items would be better presented as two separate items. The final scale consisted of 16 items, each of which described a functional activity of daily living (eg, making meals, getting in and out of bed, and participating in social activities). Respondents rated on a 5 -point scale anchored by 1 (no difficulty) and 5 (unable to do) the degree to which they had difficulty completing each activity. Total scores range from 0 to 64 , with higher scores indicating greater functional limitations.

Pain catastrophizing: The Pain Catastrophizing Scale (22) is a 13 -item scale evaluating different ways people think negatively about pain. Item responses range from 0 (not at all) to 4 (all the time). Although there are three subscales, namely, helplessness, rumination and magnification, for research purposes, a total score is commonly used. The total scale score ranges from 0 to 52 , with higher scores representing greater catastrophic thinking.

Pain self-efficacy: The Pain Self-Efficacy Questionnaire (23) was used to assess patients' confidence in their ability to enjoy life and participate in activities despite experiencing pain. This measure has 10 items, each of which is rated on a 6-point response scale ranging from 1 (not at all confident) to 6 (completely confident). Total scale scores range from 0 to 60 , with higher scores indicating greater pain self-efficacy.

Depressive symptoms: Depressive symptoms were evaluated with the widely used and psychometrically sound, 21-item, Beck Depression Inventory-II $(24,25)$. Respondents were asked to rate, the severity of depressive symptoms experienced over the previous two weeks. Each 
item has four response categories, ranging from 0 to 3 . The total scale score ranges from 0 to 63 . Higher scores denote greater depressive symptomatology.

Fear of re-injury: Fear of re-injury was assessed using the 17-item Tampa Scale of Kinesiophobia (26). This scale yields a total score ranging from 0 to 68 , with higher scores indicating a greater fear of re-injury during activity. Past research with pain populations has supported the psychometrics of this scale (27).

Global change ratings: At post-treatment, global change in pain severity and global overall change were evaluated with the Change Questionnaire for Clients (28). This scale was designed to assess minimal clinically important differences in health status. It is consistent with recommendations made by the IMMPACT consensus panel regarding the assessment of global outcomes (29), and it has been used in other published reports (30-32). Respondents rate the degree to which they changed in both domains since beginning the chronic pain management program. Responses were recorded on a 15-point scale, ranging from -7 (a very great deal worse) to +7 (a very great deal better). The mid-point of 0 corresponds to 'no change'. Positive scores indicate an improvement, whereas negative scores indicate a decline.

\section{Statistical analyses}

Data were analyzed using SPSS version 17 (IBM Corporation, USA). Basic procedures for data cleaning and screening were followed (33). Internal consistency of individual scales was evaluated using coefficient alpha.

Three pain severity categories were defined based on the 15-point global change in pain severity scale. The category 'worse pain severity' was defined as any negative score, the category 'no change in pain severity' was defined as any score of 0 , and the category 'improved pain severity' was defined as any positive score. A similar approach was taken for global overall change. Next, a repeated measures multivariate analysis of variance (MANOVA) was conducted. The within subjects factor was time (pre- and post-treatment), the between subjects factor was change in pain severity category (worse, no change, and improved) and the dependent variables were pain intensity ratings, functional limitations, pain catastrophizing, pain self-efficacy, depressive symptoms and fear of re-injury. Where applicable, post hoc tests were performed. Where relevant, effect sizes were calculated based on Cohen's d (34). Statistical significance was set at $\mathrm{P}<0.05$.

\section{RESULTS}

\section{Preliminary analyses}

A total of 400 patients began the assessment/education phase of the chronic pain management program between September 2005 and August 2008. Of these patients, 344 (86.0\%) started the treatment program. The primary reasons for not beginning treatment were psychosocial distress (18.9\%), 'poor fit' (eg, actively seeking medical intervention or other treatment) $(15.1 \%)$, unable to tolerate the physical requirements of the program $(15.1 \%)$ and medical issues requiring further investigation $(13.2 \%)$. Of the patients who started treatment, $304(88.4 \%)$ completed the program. The main reasons for dropping out were poor attendance $(30.0 \%)$, psychosocial distress (17.5\%) and medical issues requiring further investigation $(12.5 \%)$. For all patients who dropped out of the assessment/education and treatment phases, appropriate recommendations and/or referrals were made (eg, for psychological/psychiatric services or medical investigation).

Six patients completed a modified treatment program (ie, a reduced and extended treatment program primarily due to low physical tolerances) and, were therefore, excluded from the ensuing analyses. In addition, 18 patients had missing data on one or more of the global change measures and, consequently, were omitted. The final sample consisted of 280 patients who completed pre- and post-treatment measures. The final sample $(n=280)$ was compared with the patients who did not complete the treatment program or who were excluded for the aforementioned reasons $(n=120$; mean $[ \pm$ SD] age $47.5 \pm 11.4$ years;
$65 \%$ women) on basic demographic variables. No significant differences were observed. The internal consistency of all scales was satisfactory, with coefficient alphas ranging between 0.80 and 0.93 .

\section{Patient characteristics}

Of the 280 patients who completed the full treatment program, $66.1 \%(n=185)$ were women. The average age of this sample was $47.9 \pm 10.1$ years, and the mean duration of pain symptoms was $6.7 \pm 7.4$ years. The majority of patients $(n=234)$ were Caucasian. Most participants had at least some postsecondary education $(n=208)$ and approximatley one-half $(n=141)$ were not working (ie, were unemployed or receiving disability benefits). The primary pain locations were low back $(n=106)$, neck $(n=43)$, widespread/generalized $(n=32)$ and legs or feet $(n=30)$. Additional sociodemographic characteristics are presented in Table 1.

\section{Rates of reported change}

Patients' responses to the global change in pain severity scale and the global overall change scale are summarized in Table 2. The same global rating scale for these two variables was used because it allowed for the most direct and straightforward comparison. Following treatment, $35.4 \%(n=99)$ reported worse pain severity, mostly within the range of 'hardly any worse' to 'somewhat worse' ( $\mathrm{n}=63$ [63.6\%]). An additional $10.4 \%(n=29)$ reported no change in pain severity, and $54.3 \%(n=152)$ reported improved pain severity. With regards to overall change, $5.4 \%$ $(n=15)$ reported being worse, $1.4 \%(n=4)$ reported experiencing no change and $93.2 \%(n=261)$ reported being improved.

\section{Multivariate analyses}

Results of the MANOVA revealed a significant multivariate effect for time (Wilks' Lambda 0.50; F[6, 272] 44.80; P<0.001), indicating that, collapsed across groups, there was an overall difference between preand post-treatment scores. Univariate F-tests demonstrated significant improvements from pre- to post-treatment on measures of pain intensity $(\mathrm{P}<0.01)$, functional disability $(\mathrm{P}<0.001)$, depressive symptoms $(\mathrm{P}<0.001)$, pain catastrophizing $(\mathrm{P}<0.001)$, pain self-efficacy $(\mathrm{P}<0.001)$ and fear of re-injury $(\mathrm{P}<0.001)$. All effects were large, with the exception of pain intensity ratings, which was moderate. The pre-post differences on questionnaire measures are shown in Table 3.

A significant multivariate effect was obtained for pain severity groups (Wilks' Lambda 0.89; F[12, 544] 2.70; P=0.002), indicating that, collapsed across pre- and post-treatment scores, there were overall differences among patients who reported worse, no change and improved pain severity. Specifically, univariate F-tests revealed significant differences in terms of functional limitations $(\mathrm{P}=0.007)$ and pain self-efficacy $(\mathrm{P}<0.001)$. Patients who reported improved pain severity had significantly lower scores on the functional limitations scale than patients who reported worse pain severity $(\mathrm{P}<0.01)$. Patients who reported improved pain severity also had significantly higher pain self-efficacy scores than patients who reported worse pain severity $(\mathrm{P}<0.001)$. Of note, these effects are tempered by the significant interaction reported below.

Means and SDs of the dependent variables according to time and change in pain severity groups are reported in Table 4 . The significant multivariate interaction effect (Wilks' Lambda 0.78; F[12, 544] 5.98; $\mathrm{P}<0.001$ ), demonstrated differences between the change in pain severity groups over time. Post hoc tests revealed significant pre- and posttreatment differences within each of the change in pain severity groups for functional limitations, pain catastrophizing, pain self-efficacy, depressive symptoms and fear of re-injury $(\mathrm{P}<0.001$ for all). For patients reporting globally worse pain severity there was a significant increase in pain intensity, as measured by the 4-item pain scale $(\mathrm{P}<0.05)$. For the no change in pain severity group, there was no difference between pre- and post-treatment pain intensity means $(\mathrm{P}=0.38)$. For the improved pain severity group, a significant decrease in pain intensity was observed $(\mathrm{P}<0.001)$.

An examination of the pretreatment variables revealed that patients who reported reduced pain severity had higher baseline levels 
TABLE 1

Patient sociodemographic characteristics $(n=280)$

\begin{tabular}{|c|c|}
\hline Variable & \\
\hline Age, years, mean \pm SD (range) & $47.9 \pm 10.1(20-84)$ \\
\hline \multicolumn{2}{|l|}{ Sex } \\
\hline Female & 66.1 \\
\hline Male & 33.9 \\
\hline $\begin{array}{l}\text { Duration of pain symptoms, years } \\
\text { mean } \pm \mathrm{SD} \text { (range) }\end{array}$ & $\begin{array}{l}6.7 \pm 7.4 \text { ( } 4 \text { months to } \\
43.7 \text { years }\end{array}$ \\
\hline \multicolumn{2}{|l|}{ Primary pain location } \\
\hline Head, face, mouth & 3.3 \\
\hline Neck (cervical) & 15.4 \\
\hline Shoulders & 5.5 \\
\hline Arms, hands & 5.5 \\
\hline Upper back & 4.8 \\
\hline Low back & 37.9 \\
\hline Legs, feet & 10.7 \\
\hline Pelvic region & 1.1 \\
\hline Generalized & 11.4 \\
\hline Joints & 1.8 \\
\hline Other & 1.8 \\
\hline \multicolumn{2}{|l|}{ Education level } \\
\hline Primary or secondary & 25.7 \\
\hline Some college or university & 20.8 \\
\hline College or university graduate & 33.8 \\
\hline University postgraduate & 8.2 \\
\hline Trade certificate & 11.5 \\
\hline \multicolumn{2}{|l|}{ Employment status } \\
\hline Full- or part-time & 19.0 \\
\hline Unemployed & 8.2 \\
\hline Homemaker/parenting & 2.5 \\
\hline Student & 0.7 \\
\hline Short-term disability & 23.3 \\
\hline Long-term disability & 19.0 \\
\hline Sick leave & 8.2 \\
\hline Retired & 9.3 \\
\hline Other & 9.7 \\
\hline \multicolumn{2}{|l|}{ Marital status* } \\
\hline Single or never married & 11.3 \\
\hline Married & 56.7 \\
\hline Common-law & 13.5 \\
\hline Divorced & 12.4 \\
\hline Separated & 4.7 \\
\hline Widowed & 1.5 \\
\hline
\end{tabular}

Data presented as \% unless otherwise indicated. Percentages may not sum to 100 due to rounding errors. *Data are missing for five participants

of pain self-efficacy than patients who reported increased pain severity $(\mathrm{P}<0.05)$.

At post-treatment, patients who reported improved pain severity reported lower pain intensity ratings than patients who reported worse pain severity $(\mathrm{P}<0.001)$. A similar finding was observed for functional limitations, with patients who reported improved pain severity scoring lower than patients who reported worse pain severity $(\mathrm{P}<0.001)$. For depressive symptoms, patients who reported improved pain severity, as well as patients who reported no change in pain severity, reported lower scores than patients who reported worse pain severity $(\mathrm{P}<0.05)$. Finally, for pain self-efficacy, patients who reported improved pain severity scored higher than patients who reported worse pain severity $(\mathrm{P}<0.001)$.
TABLE 2

Descriptive statistics of global change ratings $(n=280)$

\begin{tabular}{lcc}
\hline & \multicolumn{2}{c}{ Change } \\
\cline { 2 - 3 } Global change rating category & In pain severity & Overall \\
\hline A very great deal worse & $1(0.4)$ & $0(0.0)$ \\
A great deal worse & $11(3.9)$ & $1(0.4)$ \\
A good deal worse & $8(2.9)$ & $4(1.4)$ \\
Moderately worse & $16(5.7)$ & $3(1.1)$ \\
Somewhat worse & $24(8.6)$ & $2(0.7)$ \\
A little worse & $16(5.7)$ & $3(1.1)$ \\
Hardly any worse & $23(8.2)$ & $2(0.7)$ \\
No change & $29(10.4)$ & $4(1.4)$ \\
Hardly any better & $25(8.9)$ & $13(4.6)$ \\
A little better & $49(17.5)$ & $50(17.9)$ \\
Somewhat better & $27(9.6)$ & $44(15.7)$ \\
Moderately better & $24(8.6)$ & $54(19.3)$ \\
A good deal better & $19(6.8)$ & $54(19.3)$ \\
A great deal better & $5(1.8)$ & $29(10.4)$ \\
A very great deal better & $3(1.1)$ & $17(6.1)$
\end{tabular}

Data presented as $n$ (\%). Percentages may not sum to 100 due to rounding errors

TABLE 3

Comparison of pre- and post-treatment measures $(n=280)$

\begin{tabular}{|c|c|c|c|c|}
\hline \multirow[b]{2}{*}{ Dependent variable } & \multicolumn{2}{|c|}{ Treatment } & \multirow[b]{2}{*}{$\mathbf{P}$} & \multirow[b]{2}{*}{ d } \\
\hline & Pre & Post & & \\
\hline Pain intensity ratings & $25.9 \pm 6.2$ & $24.2 \pm 6.3$ & $<0.001$ & 0.46 \\
\hline Functional limitations & $41.1 \pm 10.4$ & $34.6 \pm 9.7$ & $<0.001$ & 1.23 \\
\hline Depressive symptoms & $23.7 \pm 10.9$ & $16.0 \pm 10.4$ & $<0.001$ & 1.14 \\
\hline Pain catastrophizing & $27.1 \pm 11.4$ & $17.7 \pm 11.0$ & $<0.001$ & 1.36 \\
\hline Pain self-efficacy & $25.1 \pm 11.6$ & $34.7 \pm 11.6$ & $<0.001$ & 1.22 \\
\hline Fear of re-injury & $27.9 \pm 6.3$ & $23.7 \pm 6.4$ & $<0.001$ & 0.96 \\
\hline
\end{tabular}

Data presented as mean $\pm S D$ unless otherwise indicated

\section{DISCUSSION}

Previous research has evaluated adverse outcomes associated with pharmacological interventions for chronic pain; however, few studies have examined negative treatment outcomes in CBT-informed pain management programs. The present study examined patients' reports of change in perceived pain severity during interdisciplinary treatment for chronic pain.

Overall, patients endorsed significant pre- to post-treatment improvements, with large effects for most variables. This demonstrates the effectiveness of the current treatment program in improving functioning in several domains, and is consistent with previous research demonstrating the effectiveness of CBT-informed chronic pain management programs for improving patient outcomes, many of which extend beyond pain relief (3,6-10).

Slightly more than one-third of participants reported increased global pain severity at the end of treatment, whereas the rate of overall deterioration was slightly greater than $5 \%$. These are higher than the rates reported in other chronic pain research, which estimate that $1 \%$ to $2 \%$ of patients reliably deteriorate following CBT-based, inpatient treatment for chronic pain (10). These differences are likely attributable to methodological issues (eg, research design and global ratings versus statistical criteria as measures of change), program structure (eg, inpatient versus outpatient), program content (eg, components of care) and sample characteristics. Moreover, the extent to which patients endorsed worsening was generally modest, with most reporting that they were 'hardly any' to 'somewhat' worse. In the psychotherapy literature, $5 \%$ to $10 \%$ of clients routinely get worse/deteriorate while in treatment $(35,36)$. This is more in line with the present findings, especially in terms of overall change. 
TABLE 4

Dependent variables according to time and change in pain severity group $(n=280)$

\begin{tabular}{|c|c|c|c|c|c|c|}
\hline \multirow[b]{3}{*}{ Dependent variable } & \multicolumn{6}{|c|}{ Change in pain severity group } \\
\hline & \multicolumn{2}{|c|}{ Worse $(n=99)$} & \multicolumn{2}{|c|}{ No change $(n=29)$} & \multicolumn{2}{|c|}{ Improved (n=152) } \\
\hline & Pre & Post & Pre & Post & Pre & Post \\
\hline Pain intensity ratings & $25.20 \pm 7.04$ & $26.26 \pm 6.17$ & $25.70 \pm 6.21$ & $25.03 \pm 6.38$ & $26.46 \pm 5.62$ & $22.79 \pm 5.97$ \\
\hline Functional limitations & $42.41 \pm 10.29$ & $38.04 \pm 9.19$ & $39.04 \pm 8.91$ & $33.63 \pm 8.75$ & $40.65 \pm 10.60$ & $32.58 \pm 9.59$ \\
\hline Pain catastrophizing & $26.95 \pm 11.85$ & $19.82 \pm 10.84$ & $27.66 \pm 10.69$ & $16.76 \pm 11.28$ & $27.15 \pm 11.23$ & $16.53 \pm 10.92$ \\
\hline Pain self-efficacy & $22.71 \pm 11.52$ & $30.81 \pm 11.85$ & $24.00 \pm 9.17$ & $32.61 \pm 10.72$ & $26.80 \pm 11.80$ & $37.68 \pm 10.82$ \\
\hline
\end{tabular}

Data presented as mean \pm SD. Post Post-treatment; Pre Pretreatment

Although approximatley one-third of patients endorsed increased pain severity, it should be noted that the majority of patients reported a decrease in overall pain severity at program completion and, as mentioned above, there was a significant reduction in pain intensity ratings from pre- to post-treatment for the sample as a whole. One likely explanation for the increase in pain severity in some patients is that they were only starting to implement various pain management strategies over the three-week treatment phase of the program and had not yet mastered or consistently applied them (eg, working to tolerances rather than to pain, pacing activities and using relaxation techniques). Some patients reported having difficulty adjusting to the program schedule (five days per week over three treatment weeks), the program start time (ie, 08:30) and the physical demands of the fitness regimen, including the exertion of deconditioned muscles. All of this could have increased pain symptoms for some patients through increased fatigue, decreased mood and altered sleep, at least over the short-term, as they attempted to increase physical fitness through exercise.

Several variables were associated with patients' reports of increased pain severity following treatment, suggesting the presence of moderating effects (17). These included functional limitations, pain catastrophizing, pain self-efficacy and depressive symptoms. Of these variables, pain self-efficacy appeared to have one of the most robust associations. Lower baseline self-efficacy was related to patients' reports of increased pain severity. It is possible that patients who were less confident in their ability to participate in activities, despite ongoing pain, had less success in accepting changes or implementing the various pain management strategies. From a practical vantage point, increased perceived pain could potentially be ameliorated if lower self-efficacy was identified and specifically addressed by altering expectations, setting attainable goals and enhancing skills. It might be that a subset of patients with very low pretreatment pain self-efficacy scores could benefit from therapeutic work in this area before engaging in interdisciplinary chronic pain treatment programs, thereby improving outcomes for this patient group. Similar to what is suggested above, it is possible that, for a subset of patients, especially those experiencing high levels of distress, fear and negative thinking, additional intervention is required to further address one or more of these variables. This could be accomplished, for example, by addressing cognitive variables, including pain catastrophizing, especially early in treatment (37).

What remains unclear is which specific treatment-related factors might account for deterioration. Although speculative, it is possible that psychotherapeutic process variables inherent in the group-based format (eg, group cohesion, universality and instillation of hope) (38) are associated with both improvement and deterioration. For example, patients who do not feel supported or understood by other group members could be less likely to benefit from treatment. Other process variables, such as psychotherapeutic alliance (39), could be similarly associated with global change ratings. If these relationships exist, it could be beneficial to address them therapeutically both before and during treatment. Indeed, staff turnover was recently linked to poorer treatment outcomes in group treatment for persistent pain (40).

Several study limitations are acknowledged. Patients were recruited from a chronic pain management program in a rehabilitation hospital, all of whom expressed openness to the group-based, self-management approach. The current sample may not be representative of chronic pain patients encountered in other settings. Although the majority of patients completed the treatment program, some dropped out or were referred for other services. Little is known about treatment noncompleters, especially those who may have deteriorated on the global outcome measures. Although the functional limitations measure holds considerable promise (21), the modified version used in the present study has not been validated and, as such, results should be interpreted with this in mind. The correlational design and lack of a control group limit the generalizability of findings. Furthermore, change was measured at the end of the three-week treatment phase of the program, and not at later intervals after treatment.

Because the program focuses on helping patients manage their pain, it could have been beneficial to measure change several months post-treatment after patients had an opportunity to implement the skills and techniques learned. It is possible that some patients who reported deterioration (eg, in pain severity) could have experienced improvement in this domain over time (17). Finally, little is known about the clinical significance of reported change. Although several patients reported deterioration on one or more global outcomes, it was unclear whether this made a meaningful difference in their lives. Consistent with recommendations made by the IMMPACT consensus panel (29), future research could examine the degree to which patients experience treatment outcomes as clinically meaningful, as well as the degree to which participant ratings could impact and potentially improve treatment outcomes.

\section{CONCLUSION}

The current results suggest that interdisciplinary chronic pain treatment is effective for improving patients' functioning in multiple domains. Nevertheless, some patients reported increased pain severity during participation in such programs, which was associated with key variables, such as pain self-efficacy, pain catastrophizing and functional limitations.

ACKNOWLEDGEMENTS: This research was supported by the Canadian Institutes of Health Research (MOP: 93645) and the Institute for Rehabilitation Research and Development of the Ottawa Hospital Rehabilitation Centre, Ottawa, Ontario. The authors thank the Chronic Pain Management Program interdisciplinary team for their participation in this research. There are no conflicts of interest for any author. 


\section{REFERENCES}

1. Hadjistavropoulos HD, Craig KD. Acute and chronic low back pain: Cognitive, affective, and behavioral dimensions. J Consult Clin Psychol 1994;62:341-9.

2. Stewart WF, Ricci JA, Chee E, Morganstein D, Lipton R. Lost productive time and cost due to common pain conditions in the U.S. workforce. JAMA 2003;290:2443-54.

3. Turk DC. Clinical effectiveness and cost-effectiveness of treatments for patients with chronic pain. Clin J Pain 2002;18:355-65.

4. Gatchel RJ, Turk DC. Psychosocial factors in pain: Clinical perspectives. New York: Guilford Press, 1999.

5. Tunks ER, Crook J, Weir R. Epidemiology of chronic pain with psychological comorbidity: Prevalence, risk, course, and prognosis. Can J Psychiatry 2008;53:224-34.

6. Gatchel RJ, Peng YB, Peters ML, Fuchs PN, Turk DC. The biopsychosocial approach to chronic pain: scientific advances and future decisions. Psychol Bull 2007;133:581-624.

7. Keefe FJ, Abernethy AP, Campbell LC. Psychological approaches to understanding and treating disease- related pain. Annu Rev Psychol 2005;56:601-30.

8. Turk DC, Swanson KS, Tunks ER. Psychological approaches in the treatment of chronic pain patients - when pills, scalpels, and needles are not enough. Can J Psychiatry 2008;53:213-23.

9. McCracken L, Turk D. Behavioral and cognitive-behavioral treatment for chronic pain: Outcome, predictors of outcome, and treatment process. Spine 2002;27:2564-73.

10. Morley S, Williams A, Hussain S. Estimating the clinical effectiveness of cognitive behavioural therapy in the clinic: Evaluation of a CBT informed pain management programme. Pain 2008;137:670-80.

11. Turk DC, Okifuji A, Scharff L. Chronic pain and depression: role of perceived impact and perceived control in different age cohorts. J Pain 1995;61:93-101.

12. Dworkin RH, Turk DC, Farrar JT, et al. Core outcome measures for chronic pain clinical trials: IMMPACT recommendations. Pain 2005;113:9-19.

13. Turk DC, Dworkin RH, Allen RR, et al. Core outcome domains for chronic pain clinical trials: IMMPACT recommendations. Pain 2003;106:337-45.

14. Turk DC, Dworkin RH, Burke LB, et al. Initiative on Methods, Measurement and Pain Assessment in Clinical Trials. Developing patient-reported outcome measures for pain clinical trials: IMMPACT recommendations. Pain 2006;125:208-15.

15. Rodriguez RF, Bravo LE, Castro F, et al. Incidence of weak opioids adverse events in the management of cancer pain: A double blind comparative trial. Palliat Med 2007;10:56-60.

16. Barlow DH. Negative effects from psychological treatments. Am Psychol 2010;65:13-20.

17. Dimidjian S, Hollon SD. How would we know if psychotherapy were harmful? Am Psychol 2010;65:21-33.

18. Lilienfeld SO. Psychological treatments that cause harm. Perspect Psychol Sci 2007;2:53-70.

19. Jensen MP, Turner JA, Romano JM, Fisher LD. Comparative reliability and validity of chronic pain intensity measures. Pain 1999;83:157-62.

20. Von Korff M. Epidemiological and survey methods: assessment of chronic pain. In: Turk DC, Melzack R, eds. Handbook of pain assessment. New York: Guilford, 2001:603-18.
21. International Association for the Study of Pain. Pain database questionnaire. Seattle: IAPS, 1995.

22. Sullivan MJL, Bishop SR, Pivik J. The Pain Catastrophizing Scale: Development and validation. Psychol Assess 1995;7:524-32.

23. Nicholas MK. The pain self-efficacy questionnaire: taking pain into account. Eur J Pain 2007;11:153-63.

24. Beck AT, Steer RA, Brown GK. Beck Depression Inventory, 2nd edn. San Antonio: The Psychological Corporation, 1996.

25. Dozois DJ, Ahnberg JL, Dobson KS. Psychometric evaluation of the Beck Depression Inventory-II. Psychol Assess 1998;10:83-9.

26. Kori SH, Miller RP, Todd DD. Kinesiophobia: A new view of chronic pain behavior. Pain Manag 1990;3:35-43.

27. Crombez G, Vlaeyen JW, Heuts PH, Lysens R. Pain-related fear is more disabling than pain itself: Evidence on the role of pain-related fear in chronic back pain disability. Pain 1999;80:329-39.

28. Jaeschke R, Singer J, Guyatt GH. Measurement of health status: Ascertaining the minimal clinically important difference. Control Clin Trials 1989;10:407-15.

29. Dworkin RH, Turk DC, Wyrwich KW, Beaton D, Cleeland CS, Farrar JT. Interpreting the clinical importance of treatment outcomes in chronic pain clinical trials: IMMPACT recommendations. J Pain 2008;9:105-21.

30. Juniper EF, Guyatt GH, Willan A, Grifith L. Determining a minimal important change in a disease-specific quality of life questionnaire. J Clin Epidemiol 1994;47:81-7.

31. Kowal J, Wilson KG, Corace K, Henderson PR, D'Eon JL. Patients' and clinicians' global ratings of change following interdisciplinary treatment for chronic pain. J Pain Manag 2010;3:161-70.

32. Stratford PW, Binkley JM. Measurement properties of the RM-18: A modified version of the Roland-Morris Disability Scale. Spine 1997;22:2416-21.

33. Tabachnick BG, Fidell LS. Using Multivariate Statistics, 5th edn. Boston: Allyn \& Bacon/Pearson Education, 2007.

34. Cohen J. Statistical power analysis for behavioral sciences. Revised edition. New York: Academic Press, 1977.

35. Lambert, MJ, Ogles BM. The efficacy and effectiveness of psychotherapy. In: Lambert MJ, eds. Bergin and Garfield's Handbook of Psychotherapy and Behavior Change, 5th edn. New York: Wiley, 2004:139-93.

36. Mohr DC. Negative outcome in psychotherapy: A critical review. Clin Psychol Sci Pract 1995;2:1-27.

37. Burns JW, Glenn B, Bruehl S, Harden RN, Lofland K. Cognitive factors influence outcome following multidisciplinary chronic pain treatment: A replication and extension of a cross-lagged panel analysis. Behav Res Ther 2003;41:1163-82.

38. Yalom ID, Leszcz M. The Theory and Practice of Group Psychotherapy, 5th edn. New York: Basic Books, 2005.

39. Martin DJ, Garske JP, Davis MK. Relation of the therapeutic alliance with outcome and other variables: a meta-analytic review. J Consult Clin Psychol 2000;68:438-50.

40. Williams AC, Potts HWW. Group membership and staff turnover affect outcomes in group CBT for persistent pain. Pain 2010;148:481-6. 


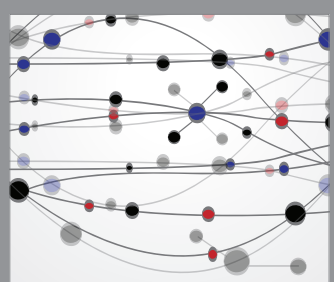

The Scientific World Journal
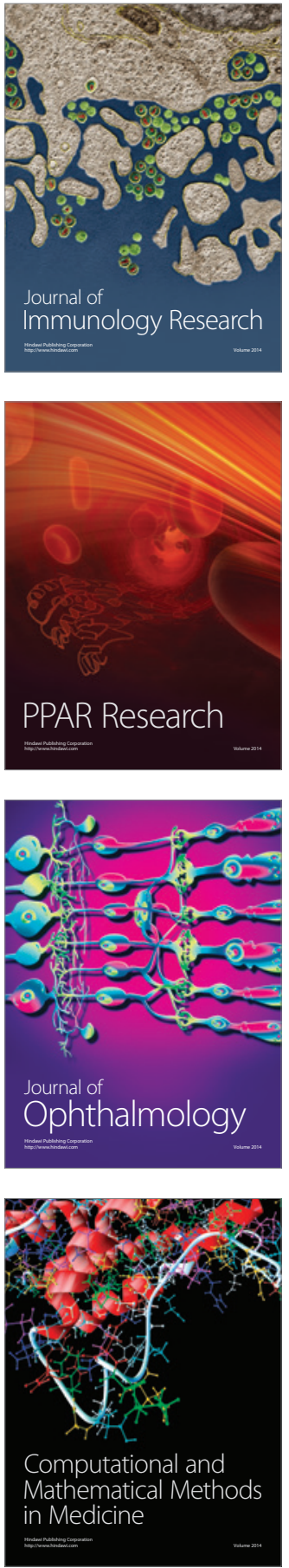

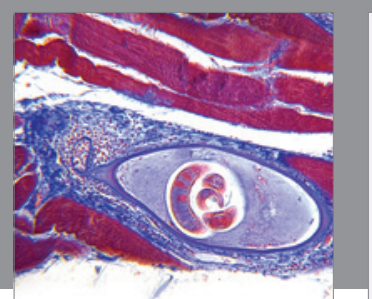

Gastroenterology Research and Practice

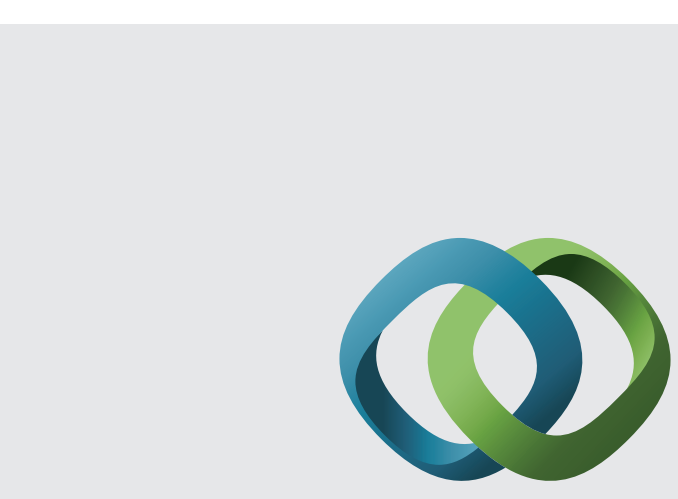

\section{Hindawi}

Submit your manuscripts at

http://www.hindawi.com
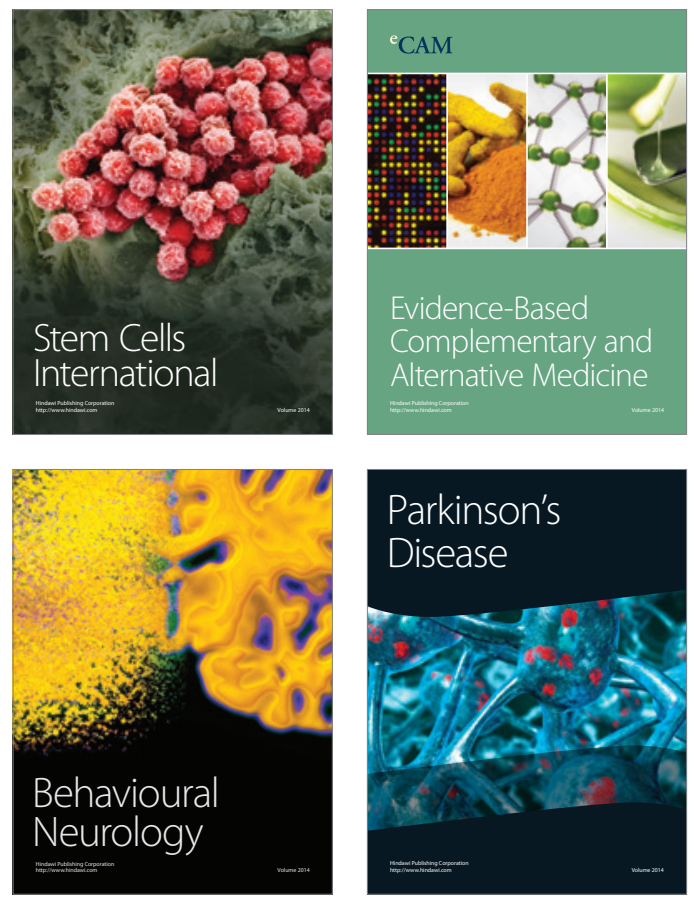
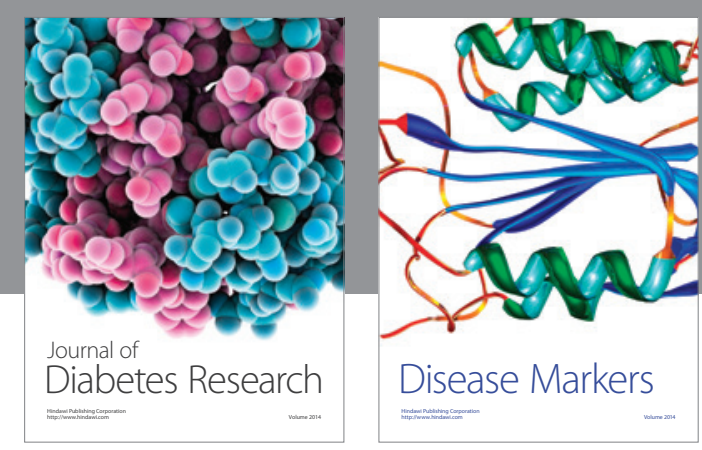

Disease Markers
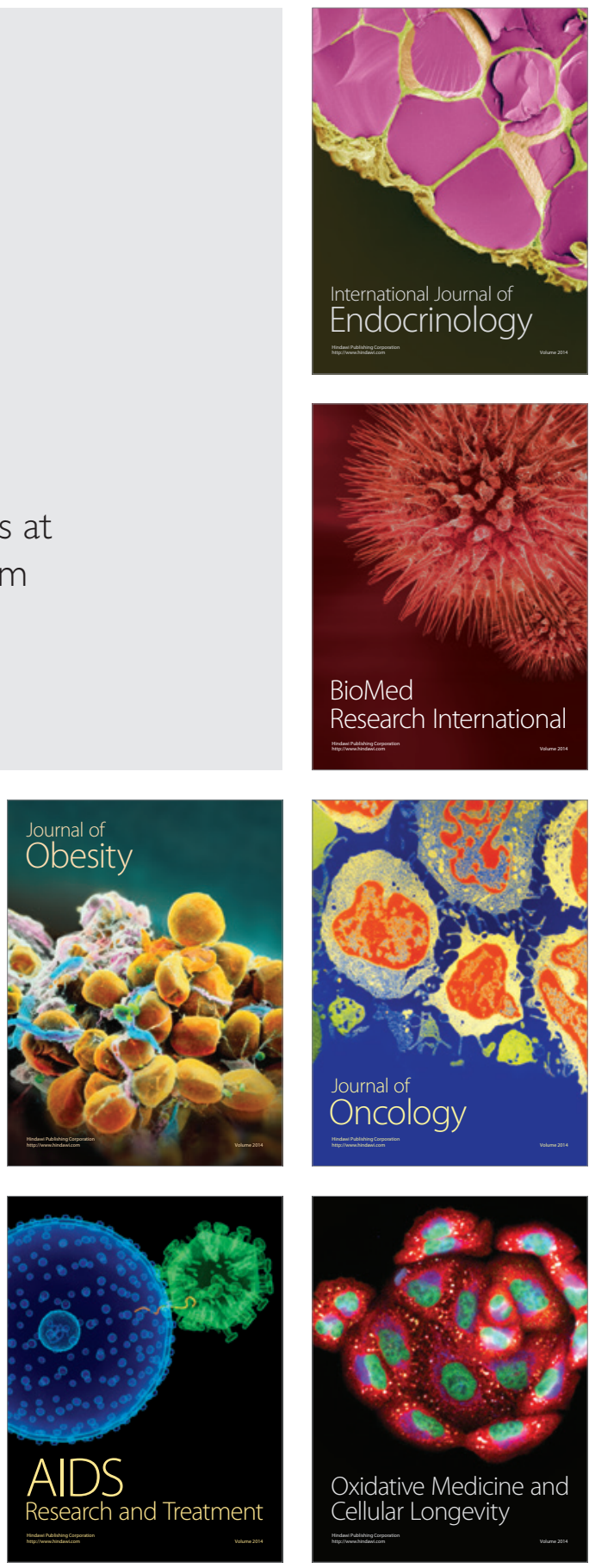